\title{
Entre a epistemologia e a ontologia A teoria da estruturação de Anthony Giddens
}

\author{
Fábio Rodrigues Ribeiro da Silva
}

Inúmeras páginas já foram escritas sobre a relação entre teoria e prática nas ciências sociais, e inúmeras mais serão. Dependendo do ponto de vista, essa relação pode ser o calcanhar de Aquiles das ciências humanas (e quem adota essa perspectiva costuma escrever "ciências" humanas, com aspas), ou seu ponto forte, uma relação inescapável com consequências quase imediatas.

Este artigo pretende oferecer uma contribuição ao debate, partindo de uma posição talvez um pouco heterodoxa. Seu objeto é a teoria social de Anthony Giddens, conhecida como teoria da estruturação. A questão é: por que essa teoria gerou, comparativamente, poucos projetos de pesquisa empírica? ${ }^{1}$ Enxergo dois caminhos para uma resposta. O primeiro seria uma investigação dos pesquisadores, uma sociologia da sociologia, para saber como escolhem fundamentações teóricas para seus trabalhos empíricos e por que a teoria da estruturação não é atraente. $\mathrm{O}$ segundo - que sigo aqui - seria uma análise da própria teoria da estruturação para identificar quais as características que atrapalhariam sua aplicação a projetos de pesquisa.

Começo então com uma breve apresentação e contextualização da obra de Giddens; em seguida, identifico as questôes metodológicas e epistemológicas que, em minha opinião, causam os problemas detectados para sua aplicação a questôes práticas; por fim, indico possíveis soluções para esses dilemas.

1. Não sou o único a chegar a essa conclusão. Ver, por exemplo, o artigo de Javier L. Cristiano (2011, p. 9): "Entre as obras que protagonizaram o último momento de expansão da teoria sociológica no início dos anos 1980, a de Anthony Giddens é talvez a que tenha tido pior sorte se considerarmos comparativamente a fixação de seus conceitos e o lugar que hoje ocupam na discussão especializada". 
2. É interessante notar que, no auge da contracultura ao final dos anos de 1960, Giddens esteve na Califórnia, o epicentro do movimento. Sobre esse período e suas possíveis influências no desenvolvimento posterior da obra de Giddens, ver o excelente artigo de Alan Sica (1991).

3. O texto clássico de Giddens contra o funcionalismo é "Funcionalismo: après la lutte" (Giddens, 1977, pp. 96-129). É sempre bom um pouco de cautela em relação a textos envoltos em polêmicas - a caracterização de Giddens do funcionalismo parsoniano é um tanto negativa demais. Para uma posição alternativa, ver, por exemplo, Hans Joas (1996).
Anthony Giddens tem uma obra imensa, que pode ser dividida em quatro momentos. O primeiro vai do início de sua carreira no final dos anos de 1960 até 1973, quando Giddens se estabelece como um importante intérprete dos clássicos da sociologia (sua obra Capitalismo e teoria social moderna, 1971, continua a ser utilizada em cursos de graduação sobre Karl Marx, Émile Durkheim e Max Weber). De 1976 a 1984, testemunhamos o desenvolvimento da teoria da estruturação, começando com Novas regras do método sociológico (1976) e culminando com $A$ constituição da sociedade (1984). A partir daí, Giddens volta sua atenção para a construção de uma teoria da modernidade, em um período que vai de $O$ Estado-nação e a violência (1987) até Modernidade e identidade (1991a). Depois de um livro de transição (Para além da esquerda e da direita, 1994), chegamos ao último período de sua obra, no qual ele se preocupa explicitamente com uma teoria política e se engaja definitivamente ao Partido Trabalhista da Grã-Bretanha. O livro-chave aqui, claro, é $A$ terceira via (1998).

O período que me interessa neste artigo é o segundo, o da elaboração da teoria da estruturação. É importante, então, contextualizá-lo. A década de 1970, como sabemos, foi um período bastante conturbado em termos políticos, econômicos e culturais ${ }^{2}$, e isso influenciou a teoria social deste período. Como vimos, Giddens participou da revitalização dos clássicos da sociologia nos anos de 1960-1970, um movimento de reinterpretação desses autores de modo diferente da tradição funcionalista (que resultou, entre outras coisas, em uma ênfase renovada em Marx). Isto, conjugado ao aparecimento de novas traduções para o inglês de autores franceses, como Claude Lévi-Strauss, e alemães, como Hans-Georg Gadamer e Jürgen Habermas, contribuiu para que autores como Giddens criassem novos projetos de renovação da teoria social.

Giddens começa identificando explicitamente um "consenso ortodoxo" funcionalista nos moldes parsonianos, cujo maior pecado, entre outros, seria ossificar a interpretação do mundo social em um molde determinista ${ }^{3}$ - uma "grande teoria" que trata de modo inadequado tanto a dimensão da ação social quanto a da estrutura social. No consenso ortodoxo, os indivíduos são "patetas culturais" (cultural dopes, expressão bastante utilizada por Giddens) à mercê das determinaçôes da sociedade, e a estrutura é concebida como um esqueleto que serve principalmente para restringir as possibilidades de ação.

Armado com um novo instrumental das escolas francesas e alemãs, além de bem informado sobre novos desenvolvimentos da filosofia da ciência 
pós-popperiana e a obra de sociólogos como Erving Goffman e Harold Garfinkel, Giddens publica as Novas regras do método sociológico em 1976. É nesse livro que encontramos a primeira formulação do que viria a ser chamado de teoria da estruturação.

Em resumo, essa teoria busca resolver o dualismo entre ação e estrutura (em que uma das dimensões é sobrevalorizada em detrimento da outra), transformando-o em uma dualidade em que nenhuma das dimensóes tem prioridade explicativa e uma depende da outra. Essa tese metateórica fundamental de Giddens é expressa como a "dualidade da estrutura": "as estruturas sociais são constituídas pela ação humana, mas ao mesmo tempo são o meio desta constituição" (Giddens, 1976, p. 121)4. Em sua obra, tanto a ação quanto a estrutura são retrabalhadas: a primeira, como uma corrente de intervenções causais de agentes hábeis em um mundo que não é predeterminado, ligada à noção de práxis; a segunda, como um conjunto virtual de regras e recursos que só é instanciado na ação. A estrutura não apenas restringe a ação, mas também a permite. Fica claro nessas poucas linhas que Giddens debate com vários conceitos e teorias muito mais complexos, e são esses debates e o desenvolvimento de sua teoria que ocuparão seus dois livros teóricos seguintes: Problemas centrais na teoria social (1979) e A constituição da sociedade (1984).

Novas regras do método sociológico é um título no mínimo ousado para uma obra de teoria social'5. Está completamente fora do escopo deste artigo uma descrição mais detalhada da teoria da estruturação, mas creio que algumas palavras sobre as "novas regras" serão úteis como transição para a discussão mais metodológica das próximas seçôes.

As novas regras são um pouco confusas porque misturam os níveis teórico e metodológico, uma confusão um tanto constante na obra de Giddens. Por exemplo, a primeira regra é claramente metodológica, um enunciado antirreducionista: "A sociologia não trata de um universo de objetos 'pré-dado', mas sim de um que é constituído ou produzido pelos fazeres ativos de sujeitos" (Giddens, 1976, p. 160). Já a segunda é teórica, uma hipótese sobre a constituição da sociedade: "A produção e reprodução da sociedade devem, portanto, ser tratadas como uma realização hábil da parte de seus membros" (Idem, ibidem). A partir daí, as regras postulam de forma mais completa a dualidade da estrutura:

O reino da ação humana é limitado. Os homens produzem a sociedade, mas fazem isso como atores localizados historicamente, e não escolhem as condições dessa pro-
4. Todas as traduçóes são de minha autoria.

5. Giddens (1976, p. 159) deixa bem claro que sua intenção com esse título é irônica: "eu não afirmo que as seguintes pressuposiçōes são 'regras' [...]. Em vez disso, elas são um enunciado resumido de alguns dos temas do estudo como um todo, e servem apenas para exemplificar suas diferenças do famoso manifesto sociológico de Durkheim [...]”. 
dução. [...] As estruturas não devem ser concebidas como simplesmente colocando limitações à ação humana, mas [também] a permitem. [...] As estruturas podem sempre, em princípio, ser examinadas em termos de sua estruturação como uma série de práticas reproduzidas. [...] Os processos de estruturação envolvem um jogo entre significados, normas e poder (Idem, pp. 160-161).

É interessante notar que Giddens considera significados, normas e poder os "termos primitivos" das ciências sociais, implicados logicamente na ação e na estrutura. De certa forma, o sociólogo move-se constantemente nesses três níveis de análise, mediados pela dualidade da estrutura. Isso serviu para Giddens introduzir um preceito metodológico hermenêutico em sua teoria:

O observador sociológico não pode transformar a vida social em um "fenômeno" para a observação independentemente do uso de seu conhecimento dela como um recurso por meio do qual ele a constitui como um "tópico para investigação". [...] A imersão numa forma de vida é o único, e necessário, meio pelo qual um observador pode gerar caracterizações [da atividade social] (Idem, p. 161).

Ou seja, o cientista social utiliza os mesmos esquemas interpretativos que os membros comuns da sociedade usam rotineiramente para compreendê-la. Foi nesse contexto que Giddens inseriu o segundo conceito fundamental da teoria da estruturação, a "hermenêutica dupla". Toda atividade científica, seja nas ciências naturais ou nas sociais, envolve um momento hermenêutico de interpretação para gerar suas descrições - talvez a principal contribuição da filosofia da ciência pós-popperiana. As ciências sociais adicionam um segundo momento hermenêutico, pois seu universo já tem seu significado constituído por seus membros, e o sociólogo precisa também reinterpretar esses esquemas de significado leigos na linguagem técnica da sociologia.

Com isto, Giddens chega ao seu resumo final das "novas regras":

6. No sentido que José Jeremias de Oliveira Filho (1995) dá ao termo: uma perspectiva metodológica, diferente do reducionismo ou do dualismo, que considera que as ciências naturais e sociais têm semelhanças mas também diferenças em seus métodos.
As tarefas principais da análise sociológica são as seguintes: (1) a explicação e a mediação hermenêuticas das formas de vida divergentes dentro das metalinguagens descritivas da ciência social; (2) a explicação da produção e da reprodução da sociedade como o resultado hábil da ação humana (Idem, p. 162).

Temos então as bases de uma teoria social com forte pendor hermenêutico e uma metodologia pluralista ${ }^{6}$. As obras subsequentes de Giddens expandem o modelo das Novas regras, trazendo, principalmente, uma reavaliação dos 
conceitos de tempo e espaço nas ciências sociais, além de discussões bem mais elaboradas das inter-relações entre ação e estrutura e também de poder e mudança social. Estes novos desenvolvimentos estão fora do escopo deste artigo, mas há uma grande guinada metodológica que concentrará minha atenção na próxima seção.

Qual é esta guinada? A saber: depois das Novas regras, Giddens passou a se referir à teoria da estruturação como uma ontologia, e não simplesmente como uma teoria. Assim, tornaram-se comuns afirmaçôes como a seguinte:

Especificamente, [a teoria da estruturação] é o rótulo que associo à minha preocupação de desenvolver um esquema ontológico para o estudo das atividades sociais humanas. Com "ontologia", quero dizer uma investigação conceitual da natureza da ação humana, das instituições sociais e das inter-relações entre ação e instituições (Giddens, 1991b, p. 201).

Antes de apontar as consequências desse "giro ontológico", acho melhor começar investigando por que ele ocorre. Primeiro, é importante enfatizar que esse giro existe. Vários comentadores, como Ira Cohen (1989), Ian Craib (1992), Christopher Bryant (1997) e Javier L. Cristiano (2011), aceitam imediatamente as proposições de Giddens sobre a teoria da estruturação como uma ontologia e partem desse princípio para seus comentários. Considero isso um equívoco. Não há nada nas Novas regras que permita identificar esse estudo como uma investigação ontológica. E interpretar a teoria da estruturação como uma ontologia desde o começo obscurece a mudança de ênfase que ocorre das Novas regras para Problemas centrais e a Constituição da sociedade.

Essa mudança tem a ver com um dos ímpetos que levou Giddens a desenvolver a teoria da estruturação - sua identificação do "consenso ortodoxo" parsoniano e o subsequente engessamento determinista da teoria social. Aqui é preciso introduzir outro elemento: a sombra cada vez maior que Habermas lança sobre a teoria social ao final dos anos de 1970 e início dos de 1980, desde sua primeira tentativa de reinterpretar a teoria e a filosofia sociais em Conhecimento e interesse (Habermas, [1968]* 1987) - que culminou em uma reinterpretação psicanalítica e linguística da teoria social que Habermas descobre insuficiente -, até a segunda tentativa, de mais fôlego, exposta na Teoria da ação comunicativa (Habermas, [1981] 1984),
*A data entre colchetes refere-se à edição original da obra. Ela é indicada na primeira vez que a obra é citada. Nas demais, indica-se somente a edição utilizada pelo autor (N. E.) 
7. Giddens chega a incluir um glossário nessa obra, tamanha a multiplicidade de conceitos criados ou reinterpretados. Ver Giddens (1984, pp. 373-377) baseada em uma reinterpretação de Weber, Durkheim, Talcott Parsons e George Herbert Mead.

Giddens enxerga Habermas caindo no mesmo buraco de Parsons, ao criar uma "grande teoria" que deixa pouco espaço para a criatividade da ação e para a contingência histórica. É importante enfatizar que um ponto-chave da teoria da estruturação é a insistência de Giddens tanto no caráter criativo da ação (o principal critério que transforma um comportamento humano numa ação social, para ele, é que o ator "poderia ter agido de outra forma”) quanto no caráter permissivo da estrutura. Sua resistência ao funcionalismo vem principalmente do determinismo embutido nas explicaçôes funcionalistas. Giddens precisa preservar o aspecto contingente da ação humana e se afastar de teorias deterministas (talvez nem fosse preciso mencionar essa condição, mas ela obviamente também afasta decisivamente a teoria da estruturação de qualquer forma de evolucionismo).

É nesse ponto que Giddens percebe que é preciso aplicar este diagnóstico de Parsons e Habermas à sua própria teoria. Como fazer com que a teoria da estruturação não se torne uma "grande teoria" determinista? A questão fica ainda mais premente com a explosão conceitual que encontramos em Problemas centrais e na Constituição da sociedade ${ }^{7}$. Meu argumento é que a transição para a ontologia é a resposta que Giddens encontrou para esse dilema.

Mais uma vez, a transição existe. Voltemos às citações que fiz anteriormente. O resumo final das Novas regras enfatiza explicaçôes: Giddens diz explicitamente que a tarefa da sociologia é explicar as formas de vida e a produção da sociedade. Esta é uma tarefa estritamente teórica - não preciso entrar aqui em detalhes epistemológicos sobre o que constitui uma explicação científica ou particularmente sociológica (questôes bastante espinhosas), mas apenas indicar a ênfase de Giddens nesse ponto de sua carreira.

A diferença para a segunda citação sobre a tarefa da sociologia é gritante. O termo "explicação" desaparece, e a teoria da estruturação torna-se um esquema ontológico para o estudo da sociedade, sendo que a ontologia é uma investigação conceitual. O que isso quer dizer? Em poucas palavras, o giro ontológico transforma a teoria da estruturação em uma tipologia conceitual que não é utilizada para gerar explicações, ou seja, sem intenção teórica. A nova posição transfere o poder explicativo para as análises sociológicas substantivas. Isso é fundamental para preservar a contingência histórica que Giddens (corretamente) tanto preza. O raciocínio aqui é que uma explicação (mais propriamente, uma hipótese explicativa) puramente teórica (como as explicações funcionais parsonianas) acaba forçando os fatos 
a se encaixarem com as teorias, e não o contrário. É por isso que Giddens quer transformar os conceitos da teoria da estruturação em "dispositivos sensibilizadores":

[...] os conceitos da teoria da estruturação, como os de qualquer perspectiva teórica rival, devem, para muitos propósitos de pesquisa, ser considerados dispositivos sensibilizadores [sensitizing devices], e nada mais. Quer dizer, eles podem ser úteis para pensar sobre problemas de pesquisa e sobre a interpretação de resultados de pesquisas (Giddens, 1984, pp. 326-327).

Ou seja, a teoria da estruturação serve para gerar esses dispositivos que auxiliam a interpretar resultados de pesquisas, mas a teoria em si não gera programas de pesquisa, nem fornece recursos para tentativas de explicação. O giro para a ontologia serve para tirar essa carga teórica possivelmente determinista dos conceitos de Giddens, deixando-os livres para sua aplicação aos mais variados programas de pesquisa empírica, a sabor do pesquisador.

Até agora vimos, primeiro, que existe o giro ontológico nos escritos de Giddens; segundo, por que ele realizou esse giro; terceiro, em que consiste o giro. Chegou o momento de tratar de suas consequências para a teoria da estruturação. É aqui que a situação se complica.

Alguns autores interpretam o giro como uma tentativa de Giddens de se esquivar de debates epistemológicos e metodológicos ${ }^{8}$ para se concentrar em outros projetos, como sua reinterpretação do materialismo histórico ${ }^{9}$ e a teoria da modernidade que ocupa o terceiro momento de sua obra que identifiquei anteriormente. Aqui é preciso alguma cautela. Certamente, não há nada que obrigue Giddens a participar de debates epistemológicos, ou mesmo a fundamentar de maneira mais explícita a teoria da estruturação (embora autores como Habermas não se furtem a essas discussões). A questão não é a falta de debates, mas as consequências disso para seu projeto teórico (ontológico?) como um todo.

Creio que essas consequências operam em dois níveis. O primeiro - que mencionarei apenas rapidamente - é um tanto esquisito. Vários comentadores notaram isso, e eu também concordo - é difícil encontrar os conceitos da teoria da estruturação na própria obra subsequente de Giddens ${ }^{10}$. Tanto a crítica do materialismo histórico quanto a teoria da modernidade não fluem diretamente da teoria da estruturação (para não falar da teoria política da terceira via dos anos de 1990). Encontramos várias "semelhanças de família”, mas é surpreendentemente complicado (e uma tarefa em aberto até hoje)
8. Bryant (1997, p. 398) é um bom exemplo: "Giddens planeja desenvolver uma ontologia do social sem participar de debates epistemológicos (pelo menos desde 1977) [...]. A ontologia é normalmente associada com a epistemologia - o que existe para conhecermos com como podemos conhecê-lo -, mas Giddens decidiu há muito tempo não entrar em debates epistemológicos".

9. Iniciada num livro muito interessante, Uma crítica contemporânea do materialismo histórico (Giddens, [1981] 1995), e desenvolvida em $O$ Estado-nação e a violência (Giddens, 1987). 10. O próprio Giddens (1990, pp. 310-315) afirma que não acha útil que a teoria da estruturação seja aplicada "como um todo" a projetos de pesquisa. 
11. Cristiano (2011) - que, como apontei no início do artigo, também identifica um problema na baixa influência da teoria de Giddens - segue um outro caminho. Ele acredita que Giddens comete equívocos em sua tentativa de preservar a contingência e busca resolver esses problemas aplicando conceitos de Cornelius Castoriadis à teoria da estruturação, mas preservando seu caráter ontológico. Embora seja uma perspectiva interessante, eu não a sigo, como veremos na sequência.

12. É claro que aqui há outra questão que deixarei apenas indicada - se o pesquisador deve mesmo querer que a teoria explique seus achados. Qualquer um que conheça os desenvolvimentos na filosofia da ciência do pós-guerra sabe que a relação entre teoria e prática não é tão simples assim. Mas, por questôes de formação, a maioria dos pesquisadores acaba replicando um positivismo e/ou realismo um tanto ingênuos em seus trabalhos. Esse campo minado é um assunto para outro dia. analisar de modo sistemático as conexões desses três âmbitos que Giddens persegue em seus escritos.

Para mim, este é um sinal de alerta que nos leva ao segundo nível das consequências do giro ontológico: o problema que identifiquei no início deste artigo, a saber, a baixa fecundidade empírica da teoria da estruturação. Esta é uma consequência irônica ou dolorosa, dependendo do ponto de vista, pois o giro ontológico, como vimos, pretendia exatamente ajudar no emprego da teoria da estruturação em projetos de pesquisa empírica. Mas não é isso que encontramos.

Como explicar essa consequência não intencional da reorientação da teoria da estruturação? Minha hipótese tem caráter pragmático ${ }^{11}$. A teoria da estruturação, ao ser esvaziada de conteúdo teórico em sua transformação em ontologia, acaba se tornando pouco útil ao pesquisador. Novamente, não é meu interesse aqui entrar no terreno da sociologia da sociologia, mas sabemos que pesquisadores empíricos utilizam teorias não apenas para "sensibilizar" seus achados e observaçôes, mas também para fundamentá-los e explicá-los. Não importa se isso ocorre por razões honestas ou desonestas (todos nós conhecemos várias obras cujos “capítulos teóricos”, normalmente no início, pouco têm a ver com a pesquisa efetivamente realizada e estão lá apenas por uma sensação de "obrigação"). Mas a teoria da estruturação é bastante complexa, com um número enorme de conceitos inter-relacionados, e, para usar termos bem diretos, exige um esforço bastante grande do pesquisador para seu aprendizado. Se o pesquisador, depois disso, descobre que não deve utilizá-la para seu objetivo (a explicação de seus achados), o que fazer? ${ }^{12}$ Há dois caminhos óbvios. O primeiro é ignorar as invectivas ontológicas de Giddens e simplesmente aplicar a teoria da estruturação como uma "grande teoria" - o que certamente pode funcionar. O segundo é encontrar outra teoria que preencha os requisitos que o pesquisador deseja. Aparentemente, é esse segundo caminho que predomina entre os pesquisadores atuais.

É possível salvar a teoria da estruturação desse destino um tanto ignóbil para um projeto teórico tão interessante? Acredito que sim. Minha tentativa nesse sentido, que não pretende de modo algum ser definitiva e/ou completa, é elaborar melhor o campo epistemológico/metodológico que Giddens basicamente abandonou em sua guinada para a ontologia. Meu raciocínio é que, com um esclarecimento mais abrangente desse campo, a teoria da 
estruturação se tornaria mais simples e útil para outros pesquisadores, adotem eles o vocabulário ontológico de Giddens ou não.

Ao mesmo tempo, este meu projeto almeja seguir as linhas esboçadas por Oliveira Filho em seu artigo programático "Reconstruções metodológicas de processos de investigação social” (1976). A ideia aqui é exatamente de que o trabalho de reconstrução metodológica é útil para esclarecer e posicionar diferentes perspectivas teórico-metodológicas, não apenas para elaborações teóricas posteriores, mas também para alimentar projetos de pesquisa empírica.

Há várias pistas na obra de Giddens - pequenas citações aqui e ali - que permitem iniciar essa reconstrução. Vários comentadores (como Craib e Cohen, já citados, mas também William Outhwaite [1990]) relacionam o projeto ontológico de Giddens com o "realismo crítico" do filósofo da ciência Roy Bhaskar ([1975] 1997; 1979). Considero isso um equívoco - é mais provável que Bhaskar tenha sido influenciado por Giddens, e não o contrário. Além disso, de qualquer forma, o projeto de Bhaskar me parece bastante infrutífero ${ }^{13}$.

Prefiro seguir um caminho menos evidente, mas sugerido pelo próprio Giddens, e enfocar a obra de outra filósofa da ciência, a inglesa Mary Hesse. Sua principal obra é $A$ estrutura da inferência científica (1974), em que ela busca reabilitar a indução científica (rejeitada, como sabemos, na famosa Lógica da pesquisa cientifica de Karl Popper [2002], livro extremamente influente) com base em um modelo probabilístico finito, organizado em redes de enunciados teóricos e de observação interligados através de inferências, que não têm prioridade uns sobre os outros, no qual todos os enunciados podem ter seus significados modificados dependendo do aparecimento de novas evidências. Esse modelo também não necessita das famosas "regras de correspondência” entre enunciados teóricos e de observação, uma característica dos modelos hipotético-dedutivos que predominaram durante o século XX. Hesse desenvolve seu modelo de redes, expandindo-o para as ciências humanas, em Revoluçôes e reconstruçôes na filosofia da ciência (1980).

Ainda que Hesse não tenha recebido o destaque que merecia entre os grandes autores da filosofia da ciência pós-popperiana, como Thomas Kuhn, Paul Feyerabend, Imre Lakatos e Larry Laudan, entre outros, não cabe aqui um aprofundamento de sua obra ${ }^{14}$. Interessa-me nesse momento mostrar a relevância do modelo de Hesse para um projeto de reconstrução da teoria da estruturação ${ }^{15}$.

As dicas estão na própria obra de Giddens. Em um dos últimos artigos que escreveu sobre questôes explicitamente metodológicas ("O positivismo
13. Não é o caso aqui de entrar em detalhes sobre esse meu diagnóstico, mas trabalhei cuidadosamente essa questão em minha tese de doutorado (cf. Silva, 2010, pp. 53-84).

14. Para isso, ver Silva (2010, pp. 21-52).

15. Dos principais comentadores de Giddens, apenas Bryant (1997, pp. 400-401) farejou o caminho que escolhi, mas não o desenvolveu. 
e seus críticos", 1977, pp. 29-89), Giddens se refere de modo bastante favorável ao modelo de Hesse e chega a propor brevemente uma utilização dele:

Podemos representar as teorias na ciência social, assim como na ciência natural, como redes envolvendo leis ou generalizações abstratas. Mas, na segunda delas, a rede não está em interação com o mundo de objetos que ela busca explicar, enquanto, na primeira, ela está. As generalizações nas ciências sociais sempre são, a princípio, instáveis em relação a seu "domínio de investigação" - ou seja, a conduta social e suas formas institucionais -, pois sua aceitação altera a relação entre a racionalização da ação e suas bases não reconhecidas. Isso é diferente das possibilidades de intervenção "técnicas" na natureza oferecidas pelas leis nas ciências naturais (Idem, p. 88).

O que temos aqui é Giddens usando o modelo de redes para expor sua concepção da hermenêutica dupla - um dos conceitos mais fundamentais da teoria da estruturação, como vimos. Depois disso, um longo silêncio (não só sobre o modelo de redes, mas também sobre temas metodológicos e epistemológicos em geral). O curioso é que, doze anos depois, ele retomou o tema das redes em um contexto bem diferente - em sua resposta aos artigos da melhor coletânea sobre a teoria da estruturação (Giddens, 1989).

Mais especificamente, Giddens respondeu às observaçōes de Richard Bernstein (1989) sobre o estatuto da teoria da estruturação enquanto teoria crítica. É quase irônico que a argumentação de Bernstein seja um espelho das reclamaçôes de comentadores preocupados com o estatuto epistemológico e metodológico da teoria da estruturação: Giddens também não fundamentaria o papel crítico da teoria social (ele apenas diz que toda teoria social é inerentemente crítica). A resposta de Giddens a Bernstein é interessante tanto porque nos permite entrever um esboço do que seria sua teoria moral, quanto por causa da retomada inesperada do modelo de redes.

Giddens, como é de costume quando se encontra entre dois extremos, busca um caminho intermediário. Nesse caso, um meio-termo entre o fundacionalismo e o relativismo no âmbito da moral. Com base no exemplo clássico weberiano da distinção entre observações fatuais e juízos de valor, ele afirma:

Mas já que [na visão de Weber] observações fatuais e juízos morais são completamente separados logicamente, o trabalho do cientista social não pode de modo algum influenciar diretamente a seleção dos próprios fins. Weber adiciona que os fins existem numa hierarquia, que pode ser seguida até algum tipo de valor ou va- 
lores definitivos. Mas esse não parece ser o caso. Sempre que examinamos qualquer debate real tratando de questões sociais e juízos relacionados, encontramos redes de juízos fatuais e axiológicos, organizados através da argumentação (Giddens, 1989, pp. 291-292).

Essa sentença final é extremamente interessante. "Redes de juízos fatuais e axiológicos, organizados através da argumentação". Minha suspeita é de que o paralelismo entre ela e "redes de enunciados teóricos e de observação interligados através de inferências", como caracterizei o projeto de Hesse, não é mera coincidência. Isso sugere que, de algum modo, o modelo de redes permanece "latente", por assim dizer, na teoria da estruturação. Giddens, em seu desejo de evitar determinismos e evolucionismos e de manter a contingência histórica e a criatividade, desconfia de dualismos irredutíveis e de hierarquias. $\mathrm{O}$ modelo de redes de Hesse se encaixa perfeitamente com essas inclinações de seu pensamento. Por isso afirmo que ele ajudaria nessa tarefa de reconstruir metodologicamente a teoria da estruturação.

Um começo dessa reconstrução já apareceu. O próprio conceito de hermenêutica dupla, um dos dois conceitos metateóricos fundamentais da obra de Giddens, poderia ser a chave para entender a teoria da estruturação como uma rede. Para colocar essa observação no paralelismo sugerido antes, podemos conceber as redes conceituais das ciências sociais como compostas de enunciados leigos e científicos interligados através da hermenêutica dupla.

Isso permite que o conceito realize seu papel metateórico de mediação entre diferentes linguagens. E, o que é mais importante, os próprios pressupostos do modelo de Hesse se coadunam com o desejo de Giddens de manter a contingência e a criatividade em contraposição ao determinismo, sem hierarquias, sem priorizar uns enunciados sobre outros. Ao mesmo tempo, pensar a teoria da estruturação dessa forma (e é preciso enfatizar que, antes de tudo, o modelo de redes é um modo de pensar - não é necessário representar os enunciados em uma "rede") permite uma relação que considero mais apropriada para pesquisadores de campo - como todos os enunciados são substituíveis, eles podem utilizar os enunciados teóricos para ajudá-los a interpretar ou mesmo explicar seus resultados. É claro que isso também significa que não é preciso aceitar a guinada ontológica de Giddens. Para mim, não se trata de uma grande perda. Por mais que eu entenda o que levou Giddens a realizar esse giro, acredito que ele criou mais problemas do que resolveu, e é em grande parte responsável pelo lugar incerto que a teoria da estruturação ocupa hoje no panorama da teoria social. 
Esbocei aqui apenas algumas linhas iniciais deste processo de reconstrução metodológica da obra de Giddens. Os próximos passos seriam explicitar melhor a organização do modelo de redes com os conceitos da teoria da estruturação, e depois expandi-la para abranger também os outros momentos de sua obra - uma tarefa enorme, mas que considero possível e desejável. Apesar de seus problemas, há muito que podemos aprender com a teoria da estruturação, tanto em termos teóricos quanto práticos. E, por que não, metodológicos.

\section{Referências Bibliográficas}

Bernstein, Richard J. (1989), "Social theory as critique". In: Held, David \& ThompSON, John B. (orgs.). Social theory of modern societies: Anthony Giddens and his critics. Cambridge, Cambridge University Press.

BHASKAR, Roy. (1979), The possibility of naturalism: a philosophical critique of the contemporary human sciences. Brighton, Harvester.

([1975] 1997), A realist theory of science. Londres, Verso.

BRYANT, Christopher. (1997), "Sociology without philosophy? The case of Giddens' structuration theory". In: \& JARY, David (orgs.). Anthony Giddens: critical assessments. Londres, Routledge, vol. 1, pp. 388-403.

CoHen, Ira J. (1989), Structuration theory: Anthony Giddens and the constitution of social life. Nova York, St. Martin's Press.

Craib, Ian. (1992), Anthony Giddens. Londres, Routledge.

Cristiano, Javier L. (2011), “Estructuración e imaginario: entre Giddens y Castoriadis". Revista Mexicana de Ciencias Politicas y Sociales, LVI (213): 9-25.

Giddens, Anthony. (1971), Capitalism and modern social theory. Cambridge, Cambridge University Press.

(1976), New rules of sociological method. Nova York, Basic Books. . (1977), Studies in social and political theory. Londres, Hutchinson. (1984), The constitution of society. Berkeley, University of California Press. . (1987), The Nation-State and violence. Berkeley, University of California Press. (1989), "A reply to my critics". In: Held, David \& Thompson, John B. (orgs.). Social theory of modern societies. Cambridge, Cambridge University Press, pp. 249-301.

. (1990), "Structuration theory and sociological analysis". In: Clark, Jon; Modgil, Celia \& ModgiL, Sohan (orgs.). Anthony Giddens: consensus and controversy. Londres, Falmer Press. 
. (1991a), Modernity and self-identity. Stanford, Stanford University Press.

. (1991b), "Structuration theory: past, present and future". In: BRYANT, Chris-

topher \& JARY, David (orgs.). Giddens' theory of structuration. Londres, Routledge. . (1994), Beyond left and right. Cambridge, Polity Press.

. ([1981] 1995), A contemporary critique of historical materialism. Stanford,

Stanford University Press.

(1998), The third way. Cambridge, Polity Press.

HaBERMAS, Jürgen. ([1981] 1984), The theory of communicative action. Boston, Beacon Press.

. ([1968] 1987), Knowledge and human interests. Cambridge, Polity Press.

Hesse, Mary. (1974), The structure of scientific inference. Berkeley, University of California Press.

. (1980), Revolutions and reconstructions in the philosophy of science. Londres,

Harvester.

JOAS, Hans. (1996), The creativity of action. Chicago, University of Chicago Press.

Oliveira Filho, José Jeremias de. (1976), “Reconstruçōes metodológicas de processos de investigação social”. Revista de História, LIV: 263-276.

. (1995), "Patologias e regras metodológicas". Estudos Avançados, 9 (23):

263-268.

Outhwaite, William. (1990), “Agency and Structure”. In: Clark, Jon; Modgil, Celia \& ModgiL, Sohan (orgs.). Anthony Giddens: consensus and controversy. Londres, Falmer Press.

Popper, Karl. (2002), The logic of scientific discovery. Londres, Routledge.

SiCA, Alan. (1991), "The California-Massachusetts strain in structuration theory".

In: BRYANT, Christopher \& JARY, David (orgs.). Giddens' theory of structuration. Londres, Routledge.

SiLVA, Fábio Rodrigues Ribeiro da. (2010), Realismo e redes: dilemas metodológicos na obra de Anthony Giddens. Tese de doutorado. São Paulo, FFLCH-USP.

\section{Resumo}

Entre a epistemologia e a ontologia: a teoria da estruturação de Anthony Giddens

$\mathrm{O}$ artigo ilustra algumas peculiaridades metodológicas do projeto teórico de Anthony Giddens, a teoria da estruturação. O diagnóstico é que ela tem menos influência na teoria social atual do que poderia ter. A causa desse problema é identificada na transição ontológica que Giddens realiza no fim dos anos de 1970, que, de modo não intencional, acaba enfraquecendo o arcabouço teórico-metodológico de seu projeto. A fim de ajudar 
a sanar o problema, sugere-se uma reconstrução metodológica com base no modelo de filosofia da ciência de Mary Hesse.

Palavras-chave: Anthony Giddens; Teoria social; Teoria da estruturação; Metodologia; Mary Hesse.

\section{Abstract}

Between epistemology and ontology: Anthony Giddens' structuration theory

The paper showcases some methodological peculiarities found in Anthony Giddens" theoretical project, structuration theory. The diagnosis is that it has less influence in current social theory than it could have. The cause of this problem is identified in the ontological transition made by Giddens in the end of the 1970s, which, unintentionally, ends up weakening the theoretical-methodological foundations of his project as a whole. A methodological reconstruction is suggested, based on Mary Hesse's model of philosophy of science, to help solve this problem.

Keywords: Anthony Giddens; Social theory; Structuration theory; Methodology; Mary Hesse. 